\title{
Drug Development Chain and Professional Curriculum Chain Integrated Pharmacy Courses
}

\author{
Haibo Yan ${ }^{1}$, Haibo Zhou², Sha $\mathrm{Li}^{2}$, Kaihe $\mathrm{Ye}^{2}$, Yunlu Jiang ${ }^{3}$, Pinghua Sun ${ }^{2, *}$ \\ ${ }^{1}$ Academic Affairs Office, Jinan University, Guangzhou, CHINA. \\ ${ }^{2}$ School of Pharmacy, Jinan University, Guangzhou, CHINA. \\ ${ }^{3}$ School of Economics, Jinan University, Guangzhou, CHINA.
}

\begin{abstract}
Background: The disjointed problem of pharmacy education training and research in the pharmaceutical industry has become increasingly prominent, restricting the "professional idea or competency transfusion" ability from pharmacy colleges and universities to the pharmaceutical industry in China. This study we proposed an integrated double-chain consisting of the "professional curriculum chain" and the "drug development chain" for successful solving this problem. Objectives: To develop the combination of pharmacy training and scientific research. Methods: Taking the feature of one student, one new lead compound as the key point, a "drug development chain" and a "professional curriculum chain" were integrated into a double-chain by a series of course and experiment redesign. Evaluation was conducted and feedback was obtained to refine the course design. Results: According to the results of a survey of recent graduates, the five years of the doublechain integration operation significantly not only promoted the professional knowledge and skills and the enthusiasm of undergraduates to participate in scientific research and innovation activities, but also optimized the teaching management mechanism in our college. Conclusion: The double-chain integration approach to pharmacy curriculum development shows convincing evidence of enhancement to the curriculum and students' research ability. Such an approach should be considered when implementing or revising pharmacy curricula.
\end{abstract}

Key words: Pharmacy, Education, Double-chain integration, Drug development chain, Professional curriculum chain, Curriculum reform.

Key Messages: This study was undertaken to solve the disjointed problem of education training and research needs. We successfully proposed an integrated double-chain consisting of the "professional curriculum chain" and the "drug development chain" by a series of course and experiment redesign. These findings indicated that the double-chain integration approach to pharmacy curriculum development shows convincing evidence of enhancement to the curriculum and students' research ability.

\section{INTRODUCTION}

With the rapid development of the medical industry in China in recent years, the disjointed problem of pharmacy education training and research in the pharmaceutical industry has become increasingly prominent, restricting the "professional idea or competency transfusion" ability from pharmacy colleges and universities to the pharmaceutical industry. ${ }^{1}$ At present, the problem of the disconnect of teaching and research is reflected mainly in three aspects.
First, the theory teaching and actual demand are disproportionate. Second, due to the verification and the passive experimental teaching mode, students' enthusiasm and education quality are less than ideal. Third, with the traditional teaching mode, ${ }^{2-4}$ students cannot fully control and understand the entire pharmaceutical discipline.

Based on the innovation platform and dominant disciplines in the College of Pharmacy of Jinan University, we proposed
Submission Date: 22-04-2020; Revision Date: 12-06-2020; Accepted Date: 13-08-2020

DOI: 10.5530/ijper.54.4.182 Correspondence: Dr. Pinghua Sun School of Pharmacy, Jinan University, Guangzhou, CHINA.

Phone: $+86-20-85221367$ E-mail: 347109811@qq.com

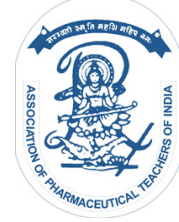

www.ijper.org 
a new type of first class innovative pharmaceutical talents training mode, that is, an integrated double-chain consisting of the "professional curriculum chain" and the "drug development chain". Through the innovation of "one new compound for each student", taking compounds independently designed by undergraduates and combining pharmaceutical main courses, integration of the professional curricular chain and the drug development chain has been achieved (Figure 1).

This implies combination of two different practical activities, the detailed procedures of innovative drug research and pilot reform courses. In order to solve the disjointed problem of education training and research needs, "drug development chain" and "professional curriculum chain" integrated method was established and applied into a series of course and experiment redesign.

\section{SUBJECTS AND METHODS}

In recent years, through studies of the professional curriculum and drug development procedures, the common features and characteristics of the integrated double-chain, have led to creation of "four bridges" (Figure 2) with which to achieve double-chain integration. The actual reform measures and the results are as follows:

The original innovation based on "medicinal chemistry". Firstly, "medicinal chemistry" was set as the foundation of the original innovation. The compulsory courses "Medicinal chemistry" and "Medicinal chemistry experiments" were the starting point indicating the direction of the original innovation in this project. ${ }^{5}$ The course design took drug discovery as its purpose. Drug discovery begins with new idea and proceeds through derivatization of lead compounds. The student is guided through the flexible application of theoretical knowledge, independent retrieval of the necessary information and independently designed experimental steps. This progression was supplemented by teacher's guidance and joint training of graduate teaching assistants forming a one-stop education mode and implements a one-student independent design and synthesis of a new compound (Figure 3). ${ }^{6}$

Since the reforms started in 2013, about 50 undergraduates have completed the self-design and synthesis of individual compounds every year and 318 new compounds have been obtained. These new compounds have been structurally identified and constructed based on which a database of specialized compounds for undergraduate courses has been assembled through the knowledge gained from the Spectrum Analysis of Organic Compounds.

\section{Establishment of a new talent training mode with new compound research as its main axis}

Secondly, a new talent training mode which cantered the new compound research as the axis was established. With the individual new compounds as the main body, practical aspects of the research and development of new drugs, such as drug purity analysis, drug efficacy screening and physicochemical properties were integrated with the basic experimental courses of pharmacy. Specialties such as "Drug Analysis" and "Pharmacology", were added to the traditional confirmatory experiment mode, to form a complete and continuous chain for drug research and development which serves as a guide to the professional course. ${ }^{7}$ Through the integration of curriculum and development chains, the problems of independence and fragmentation between courses have been solved. The practice teaching models of "drug development" and "professional curriculum" provided much feedback to the corresponding theoretical courses and enhance students' interest in theoretical knowledge. The students gained the initiative to seek knowledge and stopped to continue to passively accept professional knowledge. This has greatly promoted their enthusiasm for learning.

\section{Strengthen double-chain integration based on a comprehensive course of innovative drug design and research}

Thirdly, efforts about comprehensive courses of innovative drug design and research were made to strengthen the double-chain integration. By establishing the new course of comprehensive experiments in innovative drug design and research, active compounds obtained by early screening were studied with second level research methods such as evaluation in animals and analysis of dosage forms, to achieve integration of "pharmacy" with the drug development chain. This deepened the students' innovative ability in drug research and development while promoting achievements of the curriculum with respect to the transformation of scientific research achievements.

\section{Establish a drug research, development interactive learning and a high-quality teaching resources sharing platform}

Besides, we have built an interactive learning platform about drug research and development to share the high-quality teaching resources. In the last five years, 33 courses have been approved to enter the undergraduate courses of Jinan University. Among these, 15 courses have been accredited as AAA courses, the highest rating 
for undergraduate courses. The main pharmaceutical course, Medicinal Chemistry was established as high quality, AAA course and an excellent model course based on the online teaching platform at Jinan University. More importantly, it became a resource sharing course in Guangdong Province in 2015. Furthermore, we expect to strengthen building the educational resources, such as the sharing of excellent teaching resources, promotion of the sharing of high quality educational resources and enhancement of the students' basic knowledge of pharmacy. Meanwhile, we created a modular realtime shared assistance teaching tool based on a virtual simulation platform and a "WeChat" sharing platform. This expected to lead to teachers creating multimedia courseware of pharmacological main courses. Teachers would advance put a curriculum-related teaching syllabus, teaching programs, experiment guidance, practical projects, references and bibliographies on the above internet platform. This can also enable students to seek expansion of their knowledge course anytime and anywhere, thus guaranteeing the successful completion of the student project.

\section{Encourage young teachers to carry out teaching research and construction of teaching materials}

Apart from these works above, we also encouraged young teachers to participate in teaching research and construction of teaching materials. The established Innovative Practice Teaching Reform Association of Jinan University promoted collaboration of high-end talent with senior teachers and young teachers with the aim of team building. Convergence of the core strength of all teachers focused on the core issue of doublechain integration and adhered to the two main lines of teacher-experimenter-student and lab-internship training base-practical teaching sharing platform. Disciplinary experimental practice teaching reform, including practical education systems, experimental teaching reform and students' ability in innovation and entrepreneurship were used to develop social practice. Team teachers were encouraged to carry out research into teaching reform and construction of teaching materials. Professional curriculum materials, experimental course materials, modular knowledge and teaching resources were built too.

\section{Construction of an evaluation system for all students}

Furthermore, to assess the fruits of our reform, an effective evaluation system for students was set up. A core performance experience was constructed and an innovation award was designed as an incentive for the student evaluation system. This award was based upon use of relevant software for literature retrieval $(10 \%)$, experimental design and production of slide presentations (PowerPoint) (20\%), experimental operation (30\%), quality of the experiment report $(20 \%)$ and ability to analyze the problem $(10 \%)$ and reward $(10 \%)$. The reward included "the best design", "the best sentiment award", "a hard work award", "a 'most beautiful experiment' award" and "an experimental skills award". All of these regarded process performances rather than the final result as the main evaluation indicator of achievement for students.

\section{Develop a management system to ensure the smooth development of the curriculum}

Finally, while the curriculum reform was implemented smoothly, we also optimized an efficient management system to support the project. Team members have been working in the front line of teaching management. Training of teachers, to undertake or participate in schools focused on teaching research has a relatively rich experience in teaching research and the ability to carry out teaching research. Previous studies have provided a substantial basis for the development of this project. School and college leaders, teachers and students have all supported and cooperated in teaching reform. With the new practice of double-chain integration in training innovative talents, we have established the triangle" experimental safety management system of teacherpostgraduate assistant. This is focused on an open laboratory system, a special funding system for this project and a teacher performance incentive system. This strongly ensured the development and promotion potentials of the double-chain integration.

Through a double-chain integration mode, undergraduates were enthusiastic to participate in academic activities. The results supported students' participation in various discipline competitions, scientific and technological innovation and extracurricular scientific research activities. They were assisted by teacher guidance, team collaboration and a series reward system.

\section{Evaluation and Refinement}

Evaluation of the project was conducted by an annual survey of both graduates and senior students (Appendix 1). The survey research was granted exempt status by the Ethics Committee of First Affiliated Hospital of Jinan University and was designed specifically to assess the professional skills and attitudes in the pharmacy by questioning their level of agreement or disagreement with various statements. Questions in the survey involved the professional areas (4 groups), general capabilities (5 
groups) and curriculum coherence (1 group). In this way, a quantitative method to evaluate students' perceptions of the achievement of the double-chain integration is provided. Administration of the graduate survey began in 2013 and continued annually. We hope to track the effect of the changes in the pharmaceutical courses by monitoring student perceptions of the achievement of the desired outcomes. Apart from the annual survey, feedbacks on the effect of double-chain integration were also collected individually from students and faculty members.

\section{RESULTS}

For survey groups with more than 2 questions, the principal components analysis was conducted to identify the major exploratory factors. The multicollinearity was then conducted to calculate the weight of different exploratory factors in different survey groups and checked by examining conditioning indices and variance-decomposition proportions. ${ }^{8,9}$ The Cronbach alpha values were also calculated to assess reliability. ${ }^{10,11}$ Meanwhile, the corresponding items of each scale were combined to form scales by computing the mean score. We compared the mean levels of the 4 year outcomes by pairwise comparisons of MANOVA. Frequency analysis was used to evaluate the employment rate of the undergraduates and the rate of which undergraduates pursued higher-level education after the double-chain integration personnel training. Moreover, the teachers' participation in team building and curriculum system construction in recent years were also collected to illustrate the achievement by the double-chain integration model. For all tests, a $p$ value less than .05 was considered significant. All the analyses were performed using SPSS. ${ }^{12}$

The questionnaires were sent to all B.Pharm graduates of the past 4 years (51 graduates in 2013, 56 graduates in 2014, 48 graduates in 2015 and 48 graduates in 2016), beginning with the old curriculum through the completion of the new curriculum, are shown in Figure 4. The good news is that all the graduates responded to our survey zealously. It can be seen that all of the evaluation systems, such as professional knowledge, selflearning ability, drug development skills and particularly the professional prospect increased from 2013 to 2016. For each of the 6 exploratory factor analyses in Table 1, factors which were of interpretability was retained and each of them explained the percentage of variances of items on a scale ranging from $49.9 \%$ to $60.7 \%$.

The internal consistencies of all 8 scales for the overall sample were above the cut-off point of 0.5 and 8 of them were above 0.7 (Table 1). Among the 4 professional outcomes, students' prospect about their future which explained a majority $(60.7 \%)$ of the variance showed the most significant contribution in the 4 years reformation according to the factor analysis. Meanwhile the proportion of professional knowledge and drug design skills were also crucial for defining effectiveness of double-chain reform. The annual improvement of the above scales indicated the connection between the double-chain reform and the progress of the professional aspects. As to the general competencies, it seemed that the self-managed learning, apparently the most principal ability we trained in the double-chain reform, contributed the most to the improvements. Besides, we constructed a composite score based on the mean scores for items in each of the 8 scales. Significant differences among the mean scores of the majority of the outcome variables were obtained in the MANOVAs. Of the 10 individual composite scores, only one critical thinking, failed to achieve a significant difference among different years (Table 2), but a steady rise in the mean score of the critical thinking scales can be observed.

In 2014, a review of the project of all the courses was undertaken with a view to refining the courses and experiments. Subsequently, a recommendation was made to some of the professional course coordinators to balance the percentage of the course time and the drug development skills activities. The professional scores improved significantly in the following year.

Since the establishments of the project, 87 students have participated in innovation projects and 29 national-level projects and 28 provincial-level projects and 68 schoollevel projects have been implemented. The number of national-level projects was 57 , up $18 \%$ over the previous five years. The number of "challenge cup" projects reached 38, up nearly a half (44\%) over the previous three years. In the process of scientific research practice, we also received a series of prizes, such as "a challenge cup" for the national college students' extracurricular academic and technological work competition, the Guangdong college students' biological experimental skills and an "academic star" in Jinan University (Figure $5)$.

The double-chain integration personnel training mode focused on cultivation of advanced theoretical pharmaceutical knowledge and practical skills of pharmacy disciplines. It also covered the capability to quickly engage in clinical pharmacy, drug research and development, drug production and management, drug analysis and quality control. In the past three years, after undergraduates were exposed to doublechain integration, the overall employment rate of the 


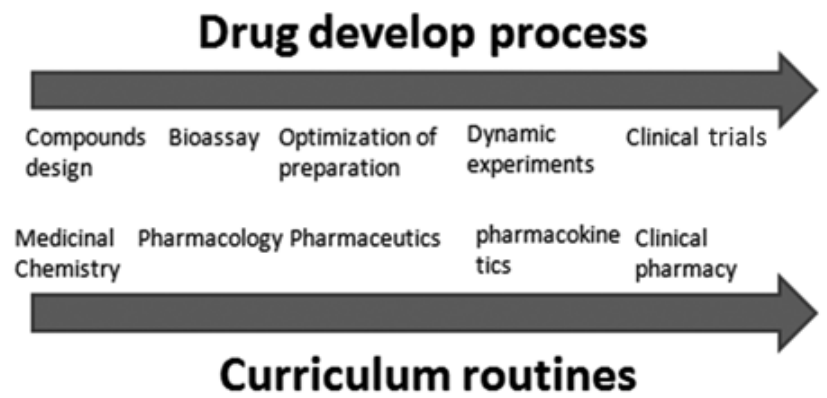

Figure 1: Training map of pharmaceutical innovation and curriculum mode.



Figure 2: The construction of the "Four Bridges" to realize double-chain integration.

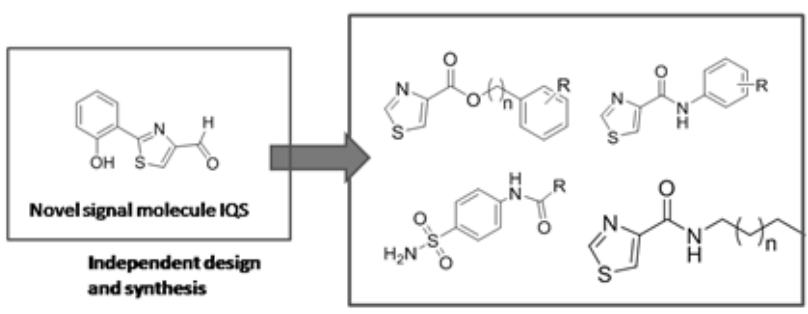

Figure 3: Independent design and synthesis of new compounds.

undergraduates rose steadily, to $91.67 \%, 96 \%$ and $100 \%$ in 2014, 2015 and 2016. More graduates have chosen to work in medical research and development and their choice of a drug discovery and development position has risen $21 \%$ over the previous three years. At the same time, the rate at which undergraduates pursued higherlevel education increased 57\%, 43 students choosing to continue their education and 11 students pursued further studies at Johns Hopkins University, King's College London or Bristol University. In 2017, all the graduates who pursued a advanced study went to the first-rate colleges and universities in China (called as $211 / 985$ project) to study in master's degree programs (Figure 6).
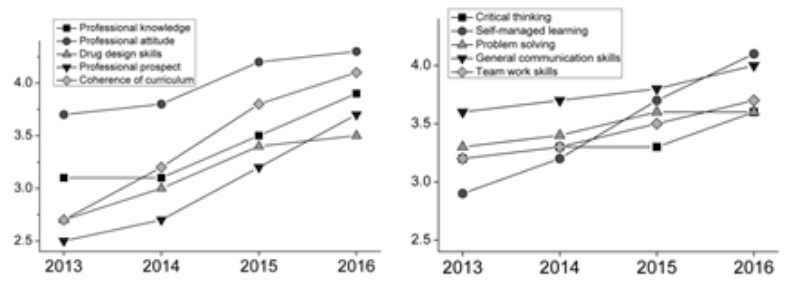

Figure 4: Longitudinal data for professional learning outcomes.

\begin{tabular}{|c|c|c|c|}
\hline Scale & $\begin{array}{l}\text { No. of } \\
\text { Items }\end{array}$ & $\begin{array}{c}\text { Variance } \\
\text { Explained by } \\
\text { the Factor, \% }\end{array}$ & $\begin{array}{c}\text { Cronbach } \\
\text { Alpha }\end{array}$ \\
\hline \multicolumn{4}{|l|}{ Professional aspects } \\
\hline $\begin{array}{l}\text { Professional } \\
\text { knowledge }\end{array}$ & 5 & 57.1 & 0.77 \\
\hline Professional attitude & 4 & 54.5 & 0.79 \\
\hline Drug design skills & 7 & 59.2 & 0.83 \\
\hline Professional prospect & 7 & 60.3 & 0.71 \\
\hline \multicolumn{4}{|l|}{$\begin{array}{c}\text { Generic } \\
\text { competencies }\end{array}$} \\
\hline Critical thinking & 2 & - & 0.69 \\
\hline $\begin{array}{l}\text { Self-managed } \\
\text { learning }\end{array}$ & 5 & 60.7 & 0.67 \\
\hline Problem solving & 4 & 49.9 & 0.76 \\
\hline $\begin{array}{c}\text { General } \\
\text { communication skills }\end{array}$ & 2 & - & 0.80 \\
\hline Team work skills & 2 & - & 0.75 \\
\hline \multicolumn{4}{|l|}{ Curriculum } \\
\hline $\begin{array}{l}\text { Coherence of } \\
\text { curriculum }\end{array}$ & 2 & - & 0.85 \\
\hline
\end{tabular}

The efficient integration of teaching and scientific research achieved by the double-chain integration model fully mobilizes the enthusiasm of teachers for teaching reform. University teachers can cause scientific research and teaching to go hand in hand, which greatly promotes the teachers' participation in team building and curriculum system construction. In the past five years, 55 teaching reform projects have been undertaken at all levels, including 12 provincial and national projects, 27 teaching research papers and 8 published papers on double-chain integration. During the implementation of this project, several teachers repeatedly achieved excellent results in the undergraduate teaching competition. Teachers in this project have published 17 books, 7 kinds of experimental materials and 14 kinds of experimental courseware. 


\begin{tabular}{|c|c|c|c|c|c|c|}
\hline & $\begin{array}{c}2013 \\
\text { Mean(SD) }\end{array}$ & $\begin{array}{c}2014 \\
\text { Mean(SD) }\end{array}$ & $\begin{array}{c}2015 \\
\text { Mean(SD) }\end{array}$ & $\begin{array}{c}2016 \\
\text { Mean(SD) }\end{array}$ & $P$ & $\begin{array}{l}\text { Tukey Procedure for } \\
\text { Pairwise Comparisons }\end{array}$ \\
\hline \multicolumn{7}{|l|}{ Professional aspects } \\
\hline $\begin{array}{l}\text { Professional } \\
\text { knowledge }\end{array}$ & $3.1(0.8)$ & $3.1(0.5)$ & $3.5(0.6)$ & $3.9(0.4)$ & .035 & $2016>2015>2014$ \\
\hline Professional attitude & $3.7(0.4)$ & $3.8(0.7)$ & $4.2(0.6)$ & $4.3(0.5)$ & .041 & $2015,2016>2013,2014$ \\
\hline Drug design skills & $2.7(0.7)$ & $3.0(0.5)$ & $3.4(0.5)$ & $3.5(0.7)$ & .017 & $2015,2016>2013,2014$ \\
\hline Professional prospect & $2.5(0.6)$ & $2.7(0.6)$ & $3.2(0.4)$ & $3.7(0.5)$ & .005 & $2016>2015>2013,2014$ \\
\hline \multicolumn{7}{|l|}{ Generic competencies } \\
\hline Critical thinking & $3.2(0.4)$ & $3.3(0.3)$ & $3.3(0.4)$ & $3.6(0.6)$ & .069 & - \\
\hline Self-managed learning & $2.9(0.5)$ & $3.2(0.5)$ & $3.7(0.6)$ & $4.1(0.4)$ & .011 & $2016>2015>2013,2014$ \\
\hline Problem solving & $3.3(0.7)$ & $3.4(0.6)$ & $3.6(0.4)$ & $3.6(0.5)$ & .047 & $2016,2015>2013,2014$ \\
\hline $\begin{array}{c}\text { General } \\
\text { communication skills }\end{array}$ & $3.6(0.7)$ & $3.7(0.5)$ & $3.8(0.6)$ & $4.0(0.7)$ & .024 & $2016>2013,2014,2015$ \\
\hline Team work skills & $3.2(0.3)$ & $3.3(0.4)$ & $3.5(0.4)$ & $3.7(0.5)$ & .035 & $2016>2015>2013$ \\
\hline \multicolumn{7}{|l|}{ Curriculum } \\
\hline $\begin{array}{l}\text { Coherence of } \\
\text { curriculum }\end{array}$ & $2.7(0.4)$ & $3.2(0.5)$ & $3.8(0.5)$ & $4.1(0.5)$ & $<.001$ & $2016>2015>2014>2013$ \\
\hline
\end{tabular}

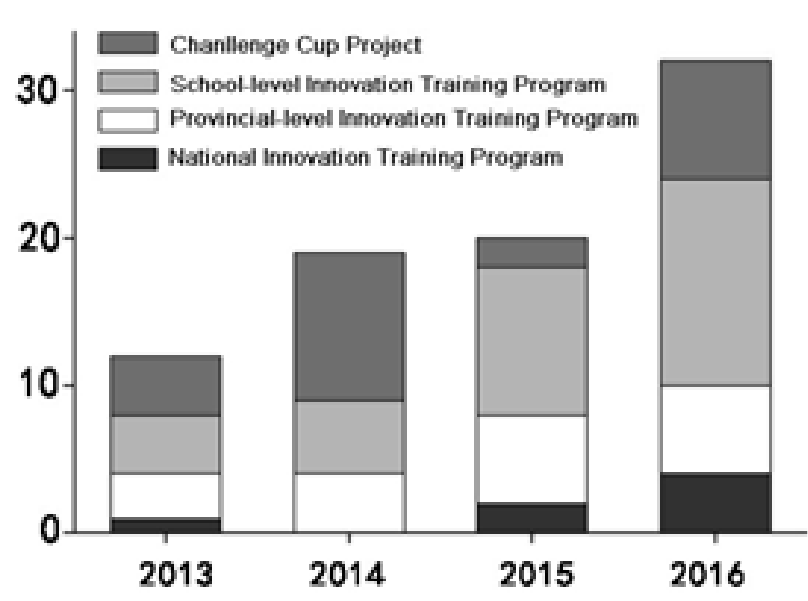

Figure 5: The growth trend of undergraduate practice after the implementation of the project.
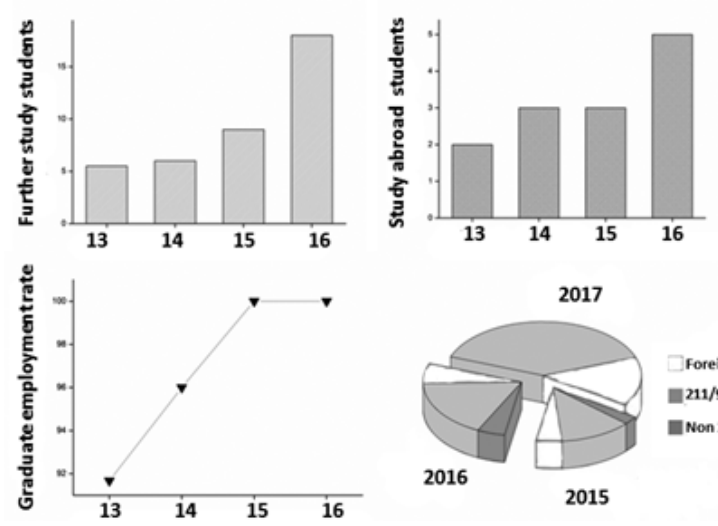

Foreign Universitie

and11/985 project

ENon 211/985

Figure 6: Graduates' admission in the recent years.

\section{DISCUSSION}

These above results proved that our double-chain integration, which is based on the professional curriculum chain integrated with the drug development chain significantly promoted the study and research abilities of the participant undergraduates. In the process of double-chain integration, the innovation mode of the whole staff has not only stimulated the interest of undergraduates in the research work, but has also increased the scientific output. In the last five years, undergraduates have made breakthrough progress in the number and level of their published scientific papers, registering a more than doubled quantity (127\%). A total of 57 academic papers were published. Of these, 27 were Science Citation Index (SCI) articles and 11 patents were applied for patents, 5 being authorized. Results have been published in highlevel journals, such as the European Journal of Medicinal Chemistry, Analyst and the Journal of Agricultural and Food Chemistry, recognizing the efficient transformation of educational and research resources. The "one person, one new compound" called for in the innovative drug design and comprehensive experiment course has since led to a library of small molecular compounds which contains 318 new compounds.

The exploratory innovation curriculum system which is dominated by the cultivation of innovative students, effectively improved the transformation and application of the student's knowledge innovation ability and the 
practice of drug research and development. The numbers of graduate students selected for further education and good evaluations from employers have both significantly improved. For nearly five years, the China Resources Double-crane Pharmaceutical Co., Ltd., Guangzhou Hanfang Pharmaceutical Co., Ltd., research institute of HEC Pharm and United Laboratories (Zhuhai, China) have compared undergraduates with the previously hired students from Jinan University. The more recently hired have a deeper understanding for development processes and ideas of pharmaceutical research and are more able to meet the requirements of research and development positions. The entry training is less than was previously required and they can be more quickly involved in actual work. Many enterprises have expressed their hope to establish a long-term cooperative relationship with College of Pharmacy of Jinan University and hope to recruit more graduates from Jinan University to participate in internships and research. By the series of curriculum reform, we have comprehensively advanced the teaching quality, the course structure optimization and the teaching management mechanism of our college.

\section{ACKNOWLEDGEMENT}

This study was supported by the research grant from the National Natural Science Foundation of China (No. 81573294), Key Project of Guangdong Province Education Reform (No. 2016JGXM_ZD_11), and $21^{\text {st }}$ batch of teaching reform research fund of Jinan University (JC2019164), 22 ${ }^{\text {nd }}$ batch of teaching reform research fund of Jinan University (JG2020151).

\section{CONFLICT OF INTEREST}

The authors declare no conflict of interests.

\section{REFERENCES}

1. Boswell C. CPhl China presents the threat and the opportunity. Cheml Market Rep. 2006;270(1): 7.

2. Robertson J, Bond C. The Research/Teaching Relation: A View from the Edge. High Educ. 2005;50(3):509-35.

3. Zhou J, Zhou S, Huang C, et al. Effectiveness of problem-based learning in Chinese pharmacy education: A meta-analysis. Bmc Medical Education. 2016;16(1):23.

4. Zhang $\mathrm{Y}$, Zhou L, Liu X, et al. The effectiveness of the problem-based learning teaching model for use in introductory Chinese undergraduate medical courses: a systematic review and meta-analysis. Plos One. 2015;10(3):e0120884.

5. Satyanarayanajois SD. Active-Learning Exercises to Teach DrugReceptor Interactions in a Medicinal Chemistry Course. Am J Pharm Educ. 2010;74(8):147.

6. Walters, Eric D. Team-Based Learning Applied to a Medicinal Chemistry Course. Med Princ Pract. 2013;22(1):2-3.

7. Beleh M, Engels M, Garcia G. Integrating a new medicinal chemistry and pharmacology course sequence into the Pharm D curriculum. Am J Pharm Educ. 2015;79(1):13.

8. Beaumont CD. Regression Diagnostics - Identifying Influential Data and Sources of Collinearity. J Oper Res Soc. 1981;32(2):157-8.

9. Grewal R, Cote JA, Baumgartner H. Multicollinearity and Measurement Error in Structural Equation Models: Implications for Theory Testing. INFORMS. 2004;23(4):519-29.

10. Miller MB. Coefficient alpha: A basic introduction from the perspectives of classical test theory and structural equation modeling. Struct Equ Modeling. 1995;2(3):255-73.

11. Schmitt N. Uses and abuses of coefficient alpha. Psychol Assessment 1996;8(4):350-3.

12. Norusis MJ. SPSS15.0 Statistical Procedures Companion Upper Saddle River, NJ: Prentice Hall. 2006.

\section{SUMMARY}

This study was undertaken to demonstrate the training model of pharmacy innovation with the double-chain integration of the drug development chain and the professional curriculum chain. Pharmaceutical innovative personnel training objectives were combined with the basic knowledge of pharmacy, comprehensive research, development of pharmaceuticals, and a strong R\&D ability. The "double-chain integration" model can be compared to a DNA double-helix: one chain is based on the main axis of independent student design of new drugs and the other corresponds to a series of medicinal chemistry, pharmacology, pharmaceutical analysis and pharmaceutics courses comprising a professional curriculum chain. The two intersect with and support each other. In this way, they form a pharmaceutical development-oriented, double-chain integration of innovative ways in which to cultivate innovative talents. This model solves a problem in higher education demand for pharmaceutical enterprises, which has reached the new height of the cultivation of innovative talents.

\section{About Authors}

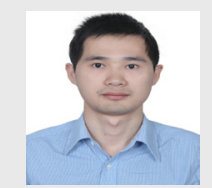

Dr. Haibo Yan, is an associate research fellow in Academic Affairs Office at Jinan University, Guangzhou, China, having total 11 years of teaching management research experience. His current research interest focuses on the curriculum development and concerns the pharmacy courses practice in the personnel training programmer. 


\section{PICTORIAL ABSTRACT}

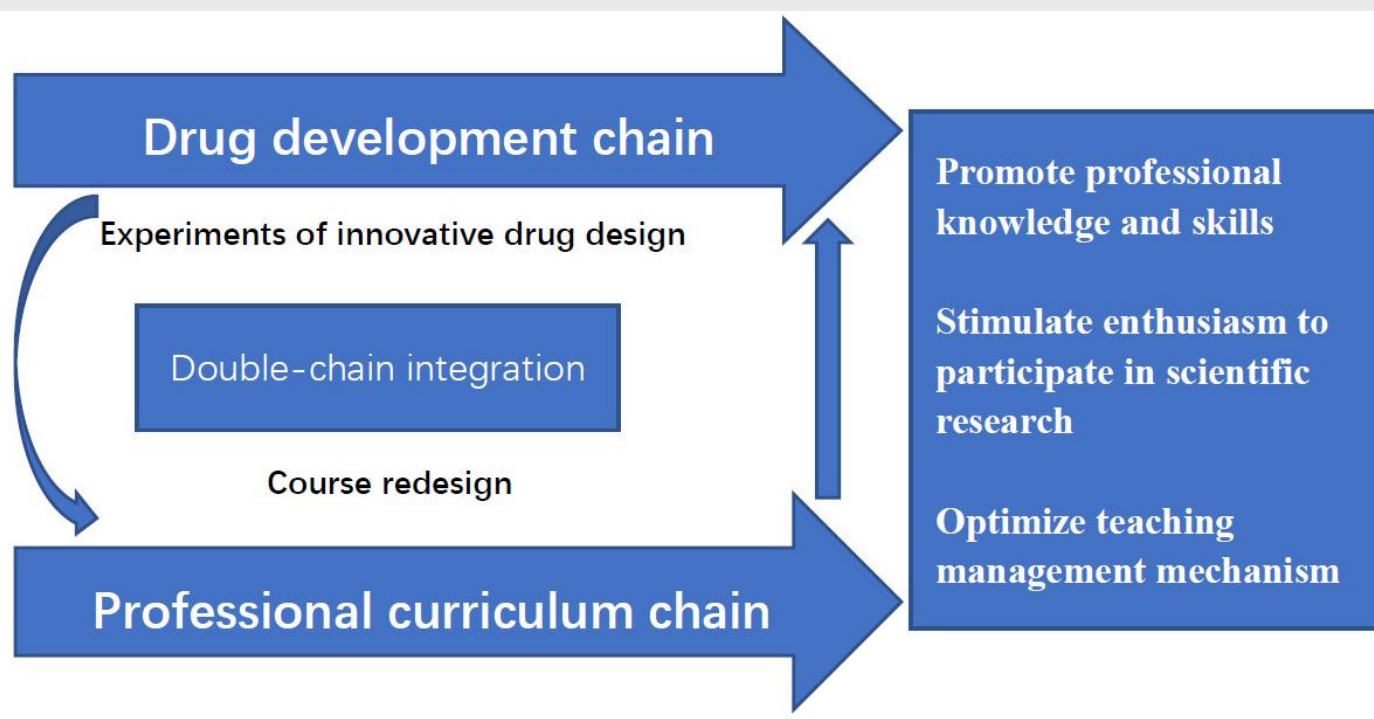

Cite this article: Yan H, Zhou H, Li S, Ye K, Jiang Y, Sun P. Drug Development Chain and Professional Curriculum Chain Integrated Pharmacy Courses. Indian J of Pharmaceutical Education and Research. 2020;54(4):888-95. 